Article

\title{
Huperzine A and Huperzine B Production by Prothallus Cultures of Huperzia selago (L.) Bernh. ex Schrank et Mart
}

\author{
Wojciech J. Szypuła ${ }^{1, *}$, Beata Wileńska ${ }^{2,3}$, Aleksandra Misicka ${ }^{2,3}$ [D and Agnieszka Pietrosiuk ${ }^{1}$ \\ 1 Department of Pharmaceutical Biology and Medicinal Plants Biotechnology, Faculty of Pharmacy, \\ Medical University of Warsaw, 1 Banacha St., 02-097 Warsaw, Poland; agnieszka.pietrosiuk@wum.edu.pl \\ 2 Faculty of Chemistry, University of Warsaw, 1 Pasteura St., 02-093 Warsaw, Poland; \\ bwilenska@chem.uw.edu.pl (B.W.); misicka@chem.uw.edu.pl (A.M.) \\ 3 Biological and Chemical Research Centre, 101 Żwirki i Wigury St., 02-097 Warsaw, Poland \\ * Correspondence: wszypula@wum.edu.pl; Tel.: +48(22)-57-20-983; Fax: +48(22)-57-20-984
}

Academic Editors: Halina Ekiert and Agnieszka Szopa

Received: 24 June 2020; Accepted: 14 July 2020; Published: 17 July 2020

check for updates

\begin{abstract}
This is the first report of an efficient and effective procedure to optimize the biosynthesis of huperzine A (HupA) and huperzine B (HupB) in vitro from Huperzia selago gametophytes. Axenic tissue cultures were established using spores collected from the sporophytes growing in the wild. The prothalia were obtained after 7-18 months. Approximately 90 up to $100 \%$ of the gametophytes were viable and grew rapidly after each transfer on to a fresh medium every 3 months. The best biomass growth index for prothallus calculated on a fresh (FW) and dry weight (DW) basis, at 24 weeks of culture, was $2500 \%$ (FW) and $2200 \%$ (DW), respectively. The huperzine A content in the gametophytes was very high and ranged from $0.74 \mathrm{mg} / \mathrm{g}$ to $4.73 \mathrm{mg} / \mathrm{g}$ DW. The highest yield HupA biosynthesis at $>4 \mathrm{mg} / \mathrm{g}$ DW was observed on W/S medium without growth regulators at 8 to 24 weeks of culture. The highest HupB content ranged from $0.10 \mathrm{mg} / \mathrm{g}$ to $0.52 \mathrm{mg} / \mathrm{g}$ DW and was obtained on the same medium. The results demonstrate the superiority of $H$. selago gametophyte cultures, with the level of HupA biosynthesis approximately $42 \%$ higher compared to sporophyte cultures and 35-fold higher than when the alkaloid was isolated from $H$. serrata, its current source for the pharmaceutical industry. Moreover, the biosynthesis of HupB was several-fold more efficient than in $H$. selago sporophytes growing in the wild. HPLC-HR-MS analyses of the extracts identified eight new alkaloids previously unreported in $\mathrm{H}$. selago: deacetylfawcettine, fawcettimine, 16-hydroxyhuperzine B, deacetyllycoclavine, annopodine, lycopecurine, des- $\mathrm{N}$-methylfastigiatine and flabelline.
\end{abstract}

Keywords: huperzine; Huperzia selago; prothallus; gametophyte; in vitro culture; secondary metabolites; Alzheimer's disease

\section{Introduction}

Huperzine A (HupA, selagine) and huperzine B (HupB) are two alkaloids which were first isolated from two Lycopodium species in the family Huperziaceae: Huperzia serrata and Huperzia selago (formerly known as L. selago) [1-4]. Pharmacological studies, in vitro, conducted in the search for novel drugs which would improve the symptoms of Alzheimer's disease (AD), have demonstrated that both compounds are potent and reversible acetylcholinesterase (AChE) inhibitors which cross the blood-brain barrier [5,6]. The currently used treatments for AD rely on the use of AChE inhibitors because acetylcholine levels in the brain increase secondary to the inhibition of the enzyme which catalyzes its breakdown, and normal function of the cholinergic system in the brain is maintained $[4,7,8]$. Acetylcholine is a neurotransmitter which plays an extremely important role in memory, and increasing its levels at the synapses improves the acetylcholine transport and ameliorates cognitive disorders 
characteristic of AD. Animal and clinical studies have demonstrated that HupA is as effective in $\mathrm{AD}$ as the approved medicinal products, but it has a superior safety profile with fewer and less severe adverse effects $[4,6,9]$. Compared to the available AChE inhibitors, such as rivastigmine, donepezil and tacrine, HupA has high oral bioavailability, produces sustained AChE inhibition and is better transported across the blood-brain barrier [9]. Recently, more medicinal properties of HupA, other than AChE inhibition, have been discovered. HupA has been found to prevent apoptosis of neurons responsible for cognition and memory via reducing oxidative stress, stimulating expression of the neuronal growth factor (NGF) gene and NGF secretion and modifying $\beta$-amyloid transformation $[6,7,10,11]$. HupA promotes the non-amyloidogenic pathway of the $\beta$-amyloid precursor protein thereby reducing its accumulation in cells [6,7]. Importantly, HupA increases the activity of the antioxidant enzymes glutathione peroxidase, superoxide dismutase and catalase and improves cell survival. Studies suggest that pharmacological properties of HupA result from its effect on the genes coding for proteins of the Bcl-2 family, Bax and p53 [6,7,11]. The overexpression of the BCL2 gene inhibits apoptosis, while the overexpression of BAX and TP53 genes induces apoptosis. In an experimental rat model, after administration of HupA followed by apoptosis-promoting stressors, proapoptotic cytosolic alterations and decreased expression of BCL2, BAX and TP53 genes were observed [6,7].

There are not many published studies on the pharmacological properties of huperzine $B$. HupB is a known potent and reversible AChE inhibitor with confirmed highly selective inhibition of AChE in the brain and less severe peripheral cholinergic side-effects [4]. According to Feng et al. [12], HupB $\left(\mathrm{IC}_{50}=1930 \mathrm{nM}\right)$ is a weaker inhibitor of $\mathrm{AChE}$ than HupA $\left(\mathrm{IC}_{50}=72.4 \mathrm{nM}\right)$. However, it has a greater therapeutic index and hence a more favorable safety profile [13]. It is a more potent agent than galantamine, but weaker than neostigmine, physostigmine and HupA [14]. It has a neuroprotective action and slows the progression of dementia [7]. It has also been demonstrated that HupB can protect neuron-like rat pheochromocytoma cells against damage caused by oxygen and glucose deprivation $[14,15]$.

The discovery of the medicinal properties of HupA, especially as a candidate drug for neurodegenerative diseases, has attracted interest in Lycopods (club mosses) as a potential source of this alkaloid for the pharmaceutical industry. Nowadays, HupA is procured from Huperzia serrata native to Asia. The excessive exploitation of the species has reduced its primary range and depleted the natural resources [15,16]. This is what happened in Yunnan Province of China where H. serrata used to be a common plant and now has the status of an endangered species $[15,16]$. A long and complicated life cycle of Lycopods is also responsible. The complete cycle from the germination of spores and the gametophyte formation to the sporophyte maturation takes at least 15 years. The mature plants are only a few centimeters in height and the HupA content in sporophytes growing in the wild is low, ranging from 0.005 to $0.01 \%$ [16-18]. In the search for alternative sources of HupA, phytochemical screening has been carried out of approximately 50 of the 400 taxa of the Lycopodiaceae sensu lato family $[5,6]$.

Huperzine A can be isolated from just a few species of the genera Huperzia and Phlegmariurus, which are members of the Huperziaceae sensu stricto family, e.g., H. herteriana, H. ovatifolia, P. carinatus, P. mingcheensis, H. pinifolia, and H. selago [5,15-17,19-21]. Lim et al. [22] found HupA in 11 of 17 investigated Huperzia species. Members of the genus Lycopodium L. and Diphasiastrum Holub (Lycopodiaceae sensu stricto), commonly found over large areas in Europe, America and Asia, are rich in a variety of alkaloids, mainly lycopodine and its derivatives [23]. As confirmed by the published studies, only a few members of the Lycopodiaceae family can synthesize HupA and HupB, which is another factor limiting the procurement of the raw plant material for the pharmaceutical industry [23].

With the growing interest in therapeutic applications of HupA, the demand for club mosses as a source of this and other alkaloids which are acetylcholinesterase inhibitors is increasing rapidly and studies on in vitro cultures of Lycopods are gaining in importance. Larger-scale HupA and HupB procurement using tissue culture techniques requires highly efficient and fast plant tissue growth and alkaloid biosynthesis in vitro [23]. Earlier studies [17,19,24] proposed ways to enhance the production 
of alkaloids and plant tissue in a variety of tissue culture models. To date, sporophytes have been mainly used as the culture-initiating material.

In the present study, we used the cultures Huperzia selago gametophytes for the biosynthesis of HupA and for the first time HupB. H. selago is the only European Huperzia species which contains HupA $[5,20,23]$ (Figure 1). Importantly, H. selago is a rich source of HupA, since its sporophytes contain much more of the alkaloid than found in Huperzia serrata native to Asia $[17,20,23]$. The preliminary studies of HupA production in in vitro culture of $H$. selago gametophytes indicate that this is a more efficient method of obtaining secondary metabolites than sporophyte culture $[17,23,25]$. So far, there have been no studies on the biosynthesis of alkaloids or any other metabolites using in vitro culture of gametophytes (prothallus). Furthermore, there have been no studies to evaluate the effects of abiotic stresses such as light intensity and its spectral quality, sugar content, agar hydration, concentrations of mineral salts or growth regulators on the biosynthesis of HupA and other alkaloids found in the Huperzia species.

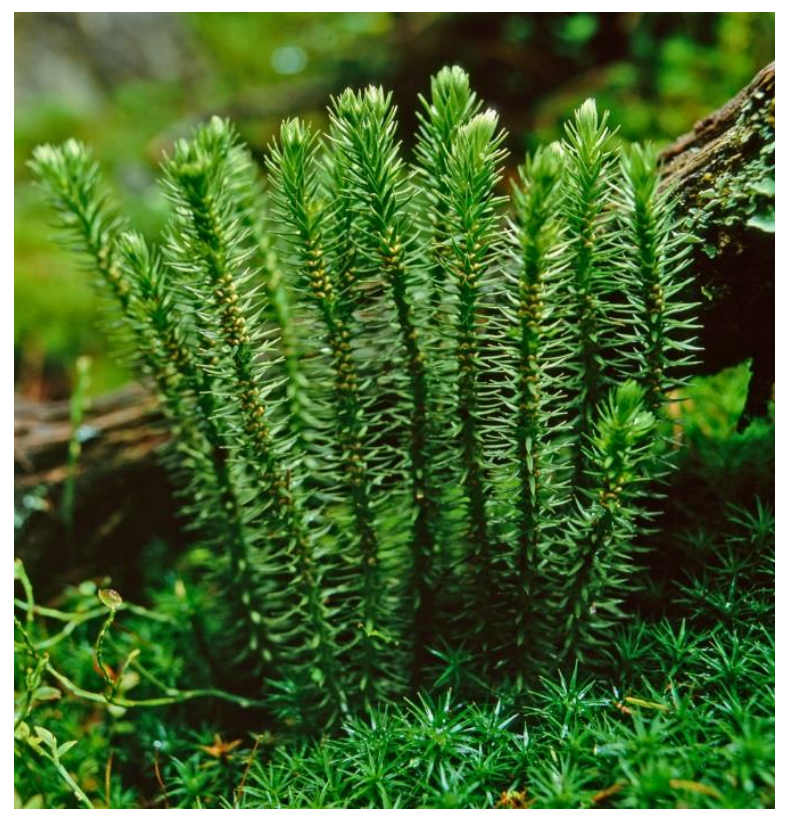

Figure 1. Fir clubmoss (Huperzia selago) sporophyte in its natural habitat in the Babia Góra National Park, Poland. Side view of the $H$. selago shoots presenting distribution of sporangia.

\section{Results}

\subsection{Establishment of In Vitro Culture and Morphological Characteristics of Gametophytes}

The spores germinated, exclusively $(0.1 \%)$ on the medium originally developed by Whittier and Storchova (W/S) and on Moore (MR) medium as modified by Freeberg and Wetmore [26,27], in the dark at 7 to 18 months of culture (Figure 2A,B). Importantly, only the spores collected in spring (April and May) germinated. At the stage of culture initiation, the spores were incubated for $24 \mathrm{~h}$ in $100 \mu \mathrm{M}$ IAA and $50 \mu \mathrm{M}$ kinetin and their walls were digested with enzymes. No spore germination and gametophyte growth were observed in repeated trials to achieve the germination of spores collected in other seasons and incubated on the other media tested. Similarly, no germination of spores which were scarified using the method of Freeberg and Wetmore [27] was observed at 24 months in culture, including the spores collected in April and May. Light was found to inhibit germination. When the same media and methods were used with which spore germination was achieved in cultures without light, no gametophytes developed during 24 months in culture in the light. With the media which allowed spore germination and further development of prothalli, the first cell division occurred inside the spore prior the wall rupture and produced two semicircular cells (Figure 2B). Their further division 
led to the development of the prothallus consisting of a few cells (Figure 2C). At 3 months in culture, the prothalli were 1-3 mm in diameter (Figure 2D). They matured after 6 to 12 months (Figure 2E-H) and did not show any signs of contamination. The mature prothalli were usually roughly square-shaped, long, narrow, axial structures with distinct dorsal and ventral surfaces (Figure 2). Most gametophytes had an hourglass- or disk-shaped cross section (Figure 2), but a smaller ventral side could cause narrower gametophytes to lose this shape (Figure 2). Generally, the mature gametophytes were dorsoventrally disk-shaped or cylindrical and branched. In culture, we also found other irregularly shaped gametophytes (carrot- or pincushion-shaped) but not filamentous-shaped gametophytes.

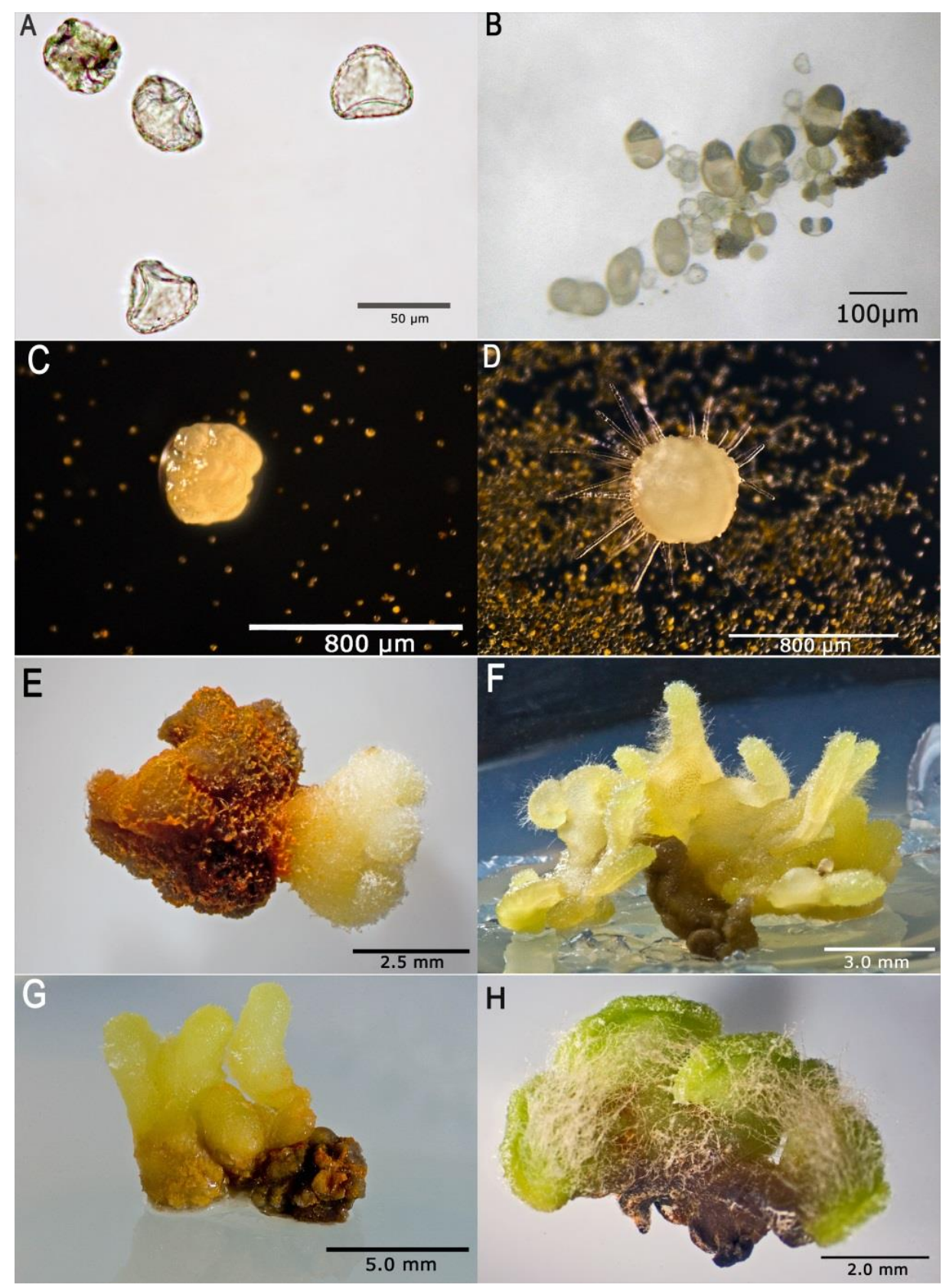

Figure 2. In vitro culture of spores and gametophytes of Huperzia selago for multiplication and an alkaloid production. (A) Spores on growth media for germination. (B) Germinating spores after 7 months of culture. (C) Young prothallus consisting of a few cells after 2-4 weeks. (D) Small spherical gametophytes after 3 months of culture. (E-H) Lateral view of different morphological types of the mature gametophyte and its late developmental stages. 
The mature gametophytes were on average 4-10 mm long (Figures 2-4). Along the apical regions of some mature prothalli, clusters of gametangia were found (Figure 3D) and embedded in the epidermis antheridia with numerous sterile paraphyses (Figure 2F,H, Figure 3, Figure 4A,B). In most of the prothalli, numerous trichomes covered the ventral surface (Figures 3 and 4A,B), but some prothalli did not develop gametangia and their ventral surface was devoid of trichomes (Figure 4C).

The vegetative part of the prothallus consisted of three distinct layers: the epidermis with heavily cutinized outer walls and trichomes, the cortex made up of several rows of ovoid cells and the palisade layer and the central parenchymatous core (Figure 3). The most important information on cultured gametophytes of Huperzia selago is summarized in Figures 2-4.

When cultures were maintained, an orange-colored secretion was observed which usually collected at the base of the ventral surface (Figure 2E). The secretion diffused into the medium changing its color. Scanning electron microscopy of the secretion found that it crystallized (Figure 4D). For chemical identification, the crystals were separated from the tissue, dissolved in methanol to prepare $1 \mathrm{mg} / \mathrm{mL}$ concentration and analyzed using HPLC-DAD (High Performance Liquid Chromatography with Diode Array Detector) to identify alkaloids. The chromatograms showed about 14-15 peaks, of which two at $10.4 \mathrm{~min}$ and $10.9 \mathrm{~min}$ corresponded to HupA and HupB, respectively.

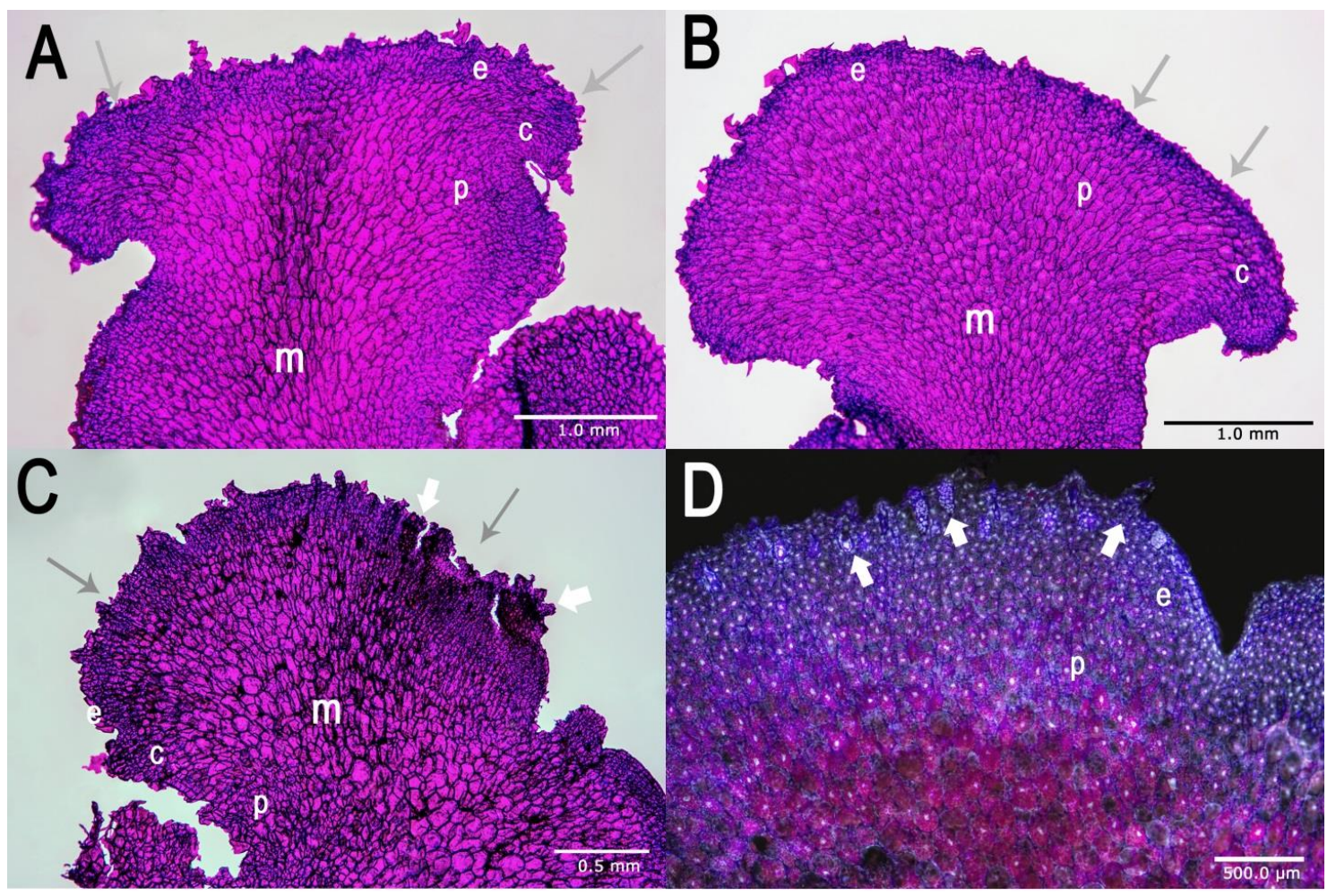

Figure 3. Light (A-C) and UV (D) micrographs of longitudinal sections of a different morphological type of Huperzia selago gametophytes. Picture shows an apical region of gametophytes with meristematic zones (arrows). Along the apical regions of some mature prothalli, clusters of gametangia were found (C,D, small white arrows); e-epidermis, c-cortex, p-palisade cells, m-central parenchymatous core. 

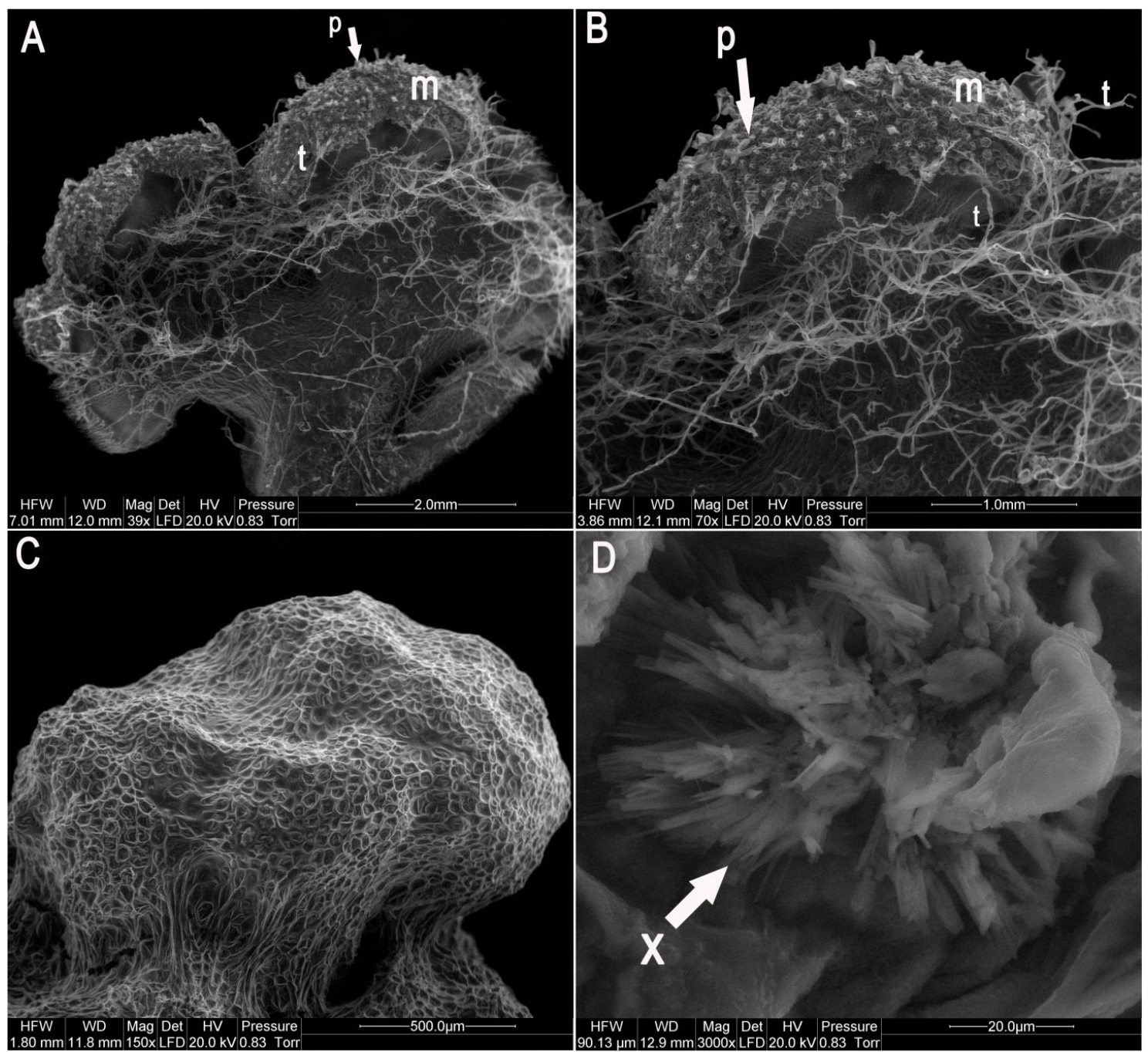

Figure 4. Development of the mature phase and adult gametophytes using SEM microscope. (A) Dorsal and ventral view of an adult, heart-shaped gametophyte. (B) Magnification ventral view of the same gametophyte. Detail of the notch showing meristematic cells with meristematic zone $(\mathrm{m})$ and embedded in the epidermis antheridia with numerous sterile paraphyses (p). In most of the gametophytes numerous trichomes covered the ventral surface $(t)$, but some prothallus $(C)$ did not develop gametangia and their ventral surface was devoid of trichomes. (D) An orange-colored crystallized secretion at the base of the ventral surface of prothallus $(\mathrm{X})$.

\subsection{Effects of Media and Growth Regulators on Cell and Biomass Growth}

The media had different effects on the growth and viability of gametophytes. The media prepared according to the method of Whittier and Storchova (W/S) [26] without growth regulators or supplemented with indole-3-butyric acid (IBA) $(0.005 \mu \mathrm{M})$ and kinetin (Kin) $(1.4 \mu \mathrm{M})$ or such media without growth regulators but supplemented with vitamins proved the most effective. Good results were also achieved on MR medium [27]. In consecutive passages, cultures on these media yielded from 90 to $100 \%$ of viable, rapidly growing gametophytes. When Murashige and Skoog ( $\left.\frac{1}{2} \mathrm{MS}\right)$ medium with modifications earlier used in the cultures of $H$. selago sporophytes was used [17], gradual slowing of the growth and development in the prothalli was observed. Data concerning the growth of gametophyte biomass on the media tested are summarized in Figure 5. The best prothallus biomass growth rate calculated on a fresh (FW) and dry weight (DW) basis at 24 weeks of culture was observed on the W/S medium without growth regulators and it was as high as $2500 \%(\mathrm{FW})$ and $2200 \%$ (DW). The mean biomass growth rate calculated for the other W/S was 2200\% (FW) and 2000\% (DW) for the medium 
with IBA $(0.05 \mu \mathrm{M})$ and $\mathrm{Kin}(1.4 \mu \mathrm{M})$ and $2000 \%$ (FW) and 1235\% (DW) for the medium without growth regulators and with addition of vitamins (Figure 5). Good results were observed with MR medium [27], when the growth rates were $1320 \%$ (FW) and 1720\% (DW). Poor gametophyte growth on Kn [28] medium and $\frac{1}{2}$ MS [17,29] medium with reduced mineral salt content was reflected in the biomass growth rates at 24 weeks, 1290\% (FW) and 700\% (DW) and 700\% (FW) and 309\% (DW), respectively, the lowest biomass growth rates observed in the present study. Variations among the mean biomass growth rates observed with some of the tested media were significantly greater than expected due to chance (Kruskal-Wallis one-way analysis of variance by ranks, $p<0.05$ ). Details are presented in Figure 5.

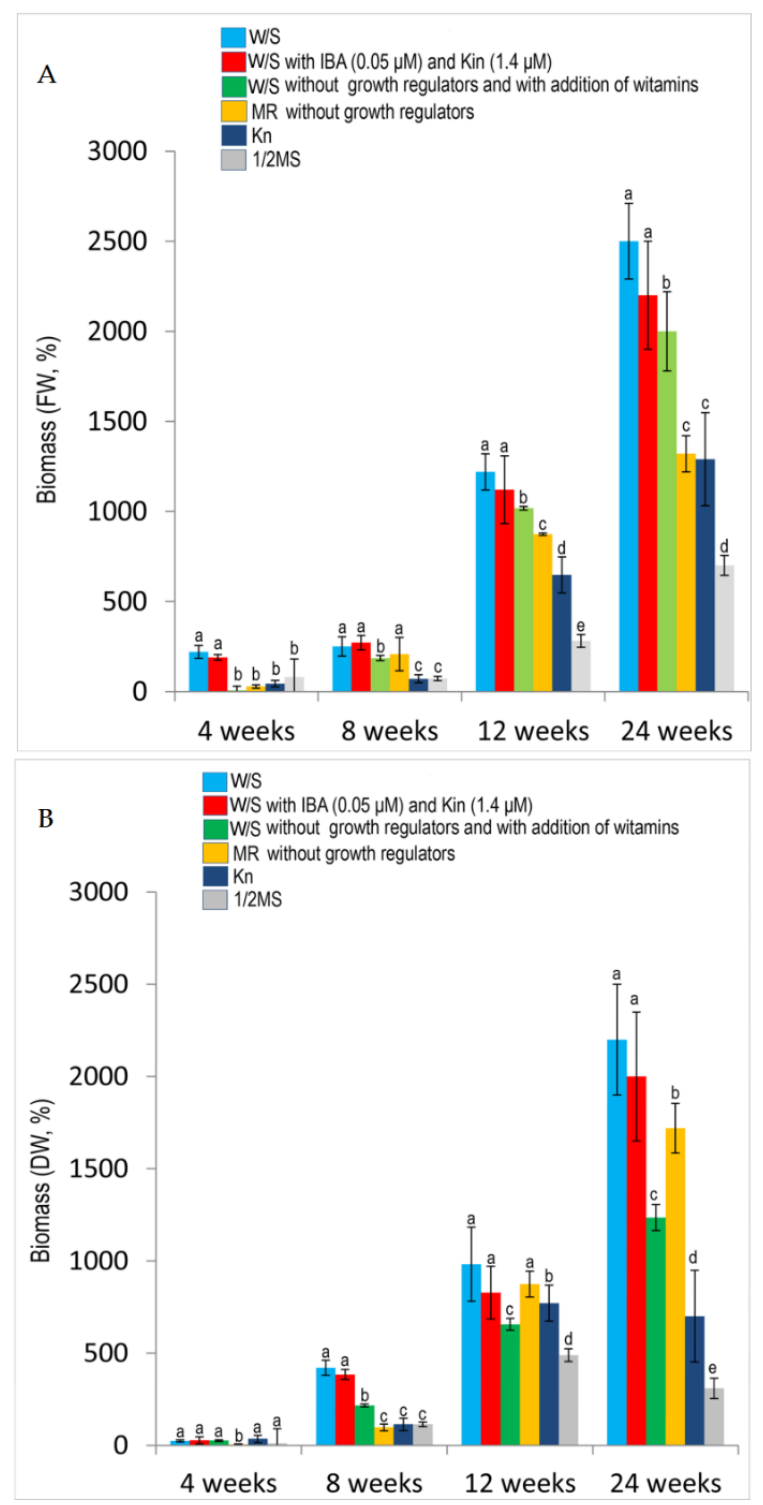

Figure 5. Effect of media and its composition on fresh (FW) (A) and dry (DW) (B) biomass increase in gametophytes culture. Data are expressed as mean \pm SD of at least three independent experiments. Significantly different values are denoted by different lowercase letters $(p<0.05)$. The statistical evaluation of the effect of media and its composition on biomass growth was evaluated in individual weeks (successively in weeks 4, 8, 12 and 24) but not between weeks.

\subsection{Characterization of Huperzia Selago Alkaloids from Gametophytes Using HPLC-DAD and Mass Spectrometry}

To determine the content of HupA and HupB and other alkaloids in H. selago gametophytes, dried alkaloid extracts were prepared and analyzed using HPLC-DAD and LCMS-IT-TOF. The extraction of 
HupA and HupB was achieved by following an established protocol [20]. The peaks corresponding to HupA and HupB were characterized by appropriate retention times, selectivity and resolution factors. The mean retention times for the HupA peak and the HupB peak were $11.67 \mathrm{~min} \pm 0.11$ and $10.11 \mathrm{~min} \pm 0.10$, respectively (Figure 6). The mean retention factor (k) for the HupA peak was $11.666 \pm 0.143 \mathrm{~min}$ and remained within the recommended range of $0.5<\mathrm{k}<20$ [30]. The UV spectrum of standard HupA and HupB ranged from 190 to $800 \mathrm{~nm}$ and showed the absorption maxima at 231.8 and $307.7 \mathrm{~nm}$ for HupA and at 222.9 and $306.8 \mathrm{~nm}$ for HupB. In the high resolution mass spectrum of standard HupA, ions with $m / z 234.1486$ (difference between theoretical and measured $m / z$ of HupA is $2.4 \mathrm{ppm}$ ) indicate the protonated ions $[\mathrm{M}+\mathrm{H}]^{+}$of HupA. For the HupB, ions with $m / z 257.1643$ (difference between theoretical and measured $\mathrm{m} / \mathrm{z}$ of HupB is $1.9 \mathrm{ppm}$ ) indicate the protonated ions $[\mathrm{M}+\mathrm{H}]^{+}$of HupB (Table 1).

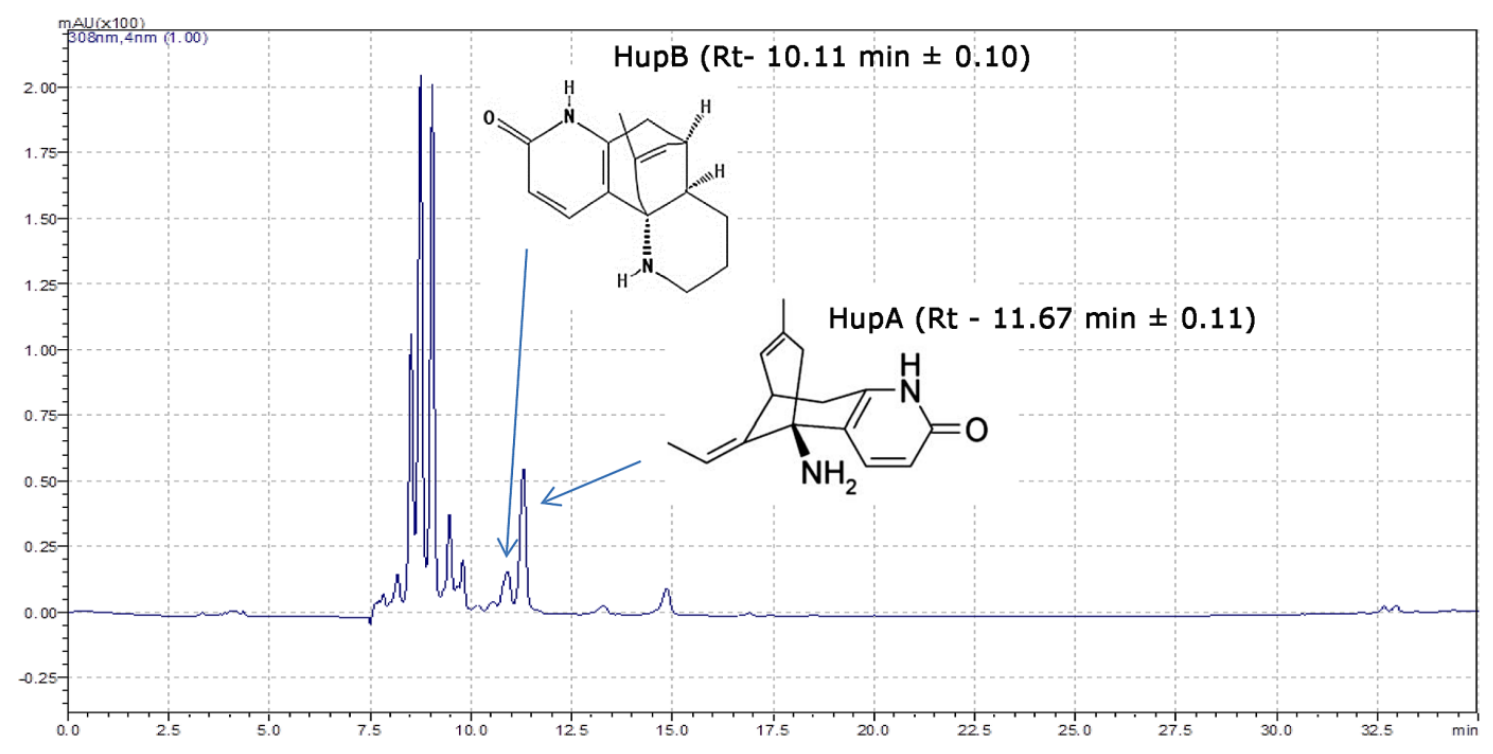

Figure 6. Sample chromatogram of H. selago extract (gametophytes from culture).

Table 1. Huperzia selago gametophyte alkaloids identified by high resolution mass spectrometry and Formula Predictor software.

\begin{tabular}{ccccc}
\hline An alkaloid Name & Formula & Theoretical Mass & Measured Mass & $m / z$ Error $(\mathbf{p p m})$ \\
\hline Fawcettimine & $\mathrm{C}_{16} \mathrm{H}_{25} \mathrm{NO}_{2}$ & 264.1958 & 264.1962 & 1.51 \\
Deacetylfawcettine & $\mathrm{C}_{16} \mathrm{H}_{27} \mathrm{NO}_{2}$ & 266.2115 & 266.2109 & -2.25 \\
6 3 -hydroxyhuperzine A & $\mathrm{C}_{15} \mathrm{H}_{18} \mathrm{~N}_{2} \mathrm{O}_{2}$ & 259.1441 & 259.1431 & -3.86 \\
16-hydroxyhuperzine B & $\mathrm{C}_{16} \mathrm{H}_{21} \mathrm{~N}_{2} \mathrm{O}_{2}$ & 273.1598 & 273.1599 & 0.37 \\
Deacetyllycoclavine & $\mathrm{C}_{16} \mathrm{H}_{27} \mathrm{NO}_{2}$ & 266.2115 & 266.2109 & -2.25 \\
Huperzine B & $\mathrm{C}_{16} \mathrm{H}_{20} \mathrm{~N}_{2} \mathrm{O}$ & 257.1648 & 257.1642 & -2.33 \\
Huperzine A & $\mathrm{C}_{15} \mathrm{H}_{18} \mathrm{~N}_{2} \mathrm{O}$ & 243.1492 & 243.1481 & -4.52 \\
Serratinidine & $\mathrm{C}_{18} \mathrm{H}_{28} \mathrm{~N}_{2} \mathrm{O}_{2}$ & 305.2224 & 305.2217 & -2.29 \\
Annopodine & $\mathrm{C}_{17} \mathrm{H}_{25} \mathrm{NO}_{3}$ & 292.1907 & 292.1901 & -2.05 \\
Lycopodine & $\mathrm{C}_{16} \mathrm{H}_{25} \mathrm{NO}$ & 248.2009 & 248.2002 & 2.82 \\
Selagoline & $\mathrm{C}_{16} \mathrm{H}_{25} \mathrm{NO}$ & 248.2009 & 248.1998 & -4.48 \\
Lycopecurine & $\mathrm{C}_{16} \mathrm{H}_{27} \mathrm{NO}$ & 250.2165 & 250.2156 & -3.60 \\
Des- $N$-methylfastigiatine & $\mathrm{C}_{18} \mathrm{H}_{26} \mathrm{~N}_{2} \mathrm{O}$ & 287.2118 & 287.2113 & -1.74 \\
Flabelline & $\mathrm{C}_{18} \mathrm{H}_{29} \mathrm{~N}_{2} \mathrm{O}$ & 289.2274 & 289.2275 & 0.35 \\
\hline
\end{tabular}

In total, using high resolution mass spectrometry and Formula Predictor software (Shimadzu, Kyoto, Japan), 14 compounds were identified based on the comparison of their theoretical mass and molecular formula (based on the literature data) with measured mass and proposed molecular formula (Table 1). Most of these were known compounds earlier isolated from sporophytes of Lycopodiaceae 
sensu lato but never from the prothallus, which confirmed that most, if not all, of these identifications were valid.

\subsection{Effects of Different Media and Their Composition on Huperzine A and Huperzine B Production}

The content of huperzine $\mathrm{A}$ in the gametophytes from in vitro culture was very high and ranged from $0.74 \mathrm{mg} / \mathrm{g}$ to $4.73 \mathrm{mg} / \mathrm{g}$ dry weight (DW) (Figure 6). The highest HupA content, $4.73 \mathrm{mg} / \mathrm{g} \mathrm{DW}$, was found in the gametophytes at 8 weeks of culture on W/S medium without growth regulators. With the same medium, the highest stable increase in the biosynthesis of HupA during the entire culture period was observed: $2.35 \mathrm{mg} / \mathrm{g}$ DW at 4 weeks to over $4.0 \mathrm{mg} / \mathrm{g}$ DW in the subsequent weeks (Figure 7). Importantly, from 8 to 24 weeks of culture this increase in the HupA content with W/S medium was statistically significant in comparison to cultures using the other media. The mean HupA content in gametophytes during 24 weeks of culture on W/S medium was $3.84 \pm 0.27 \mathrm{mg} / \mathrm{g}$ DW.

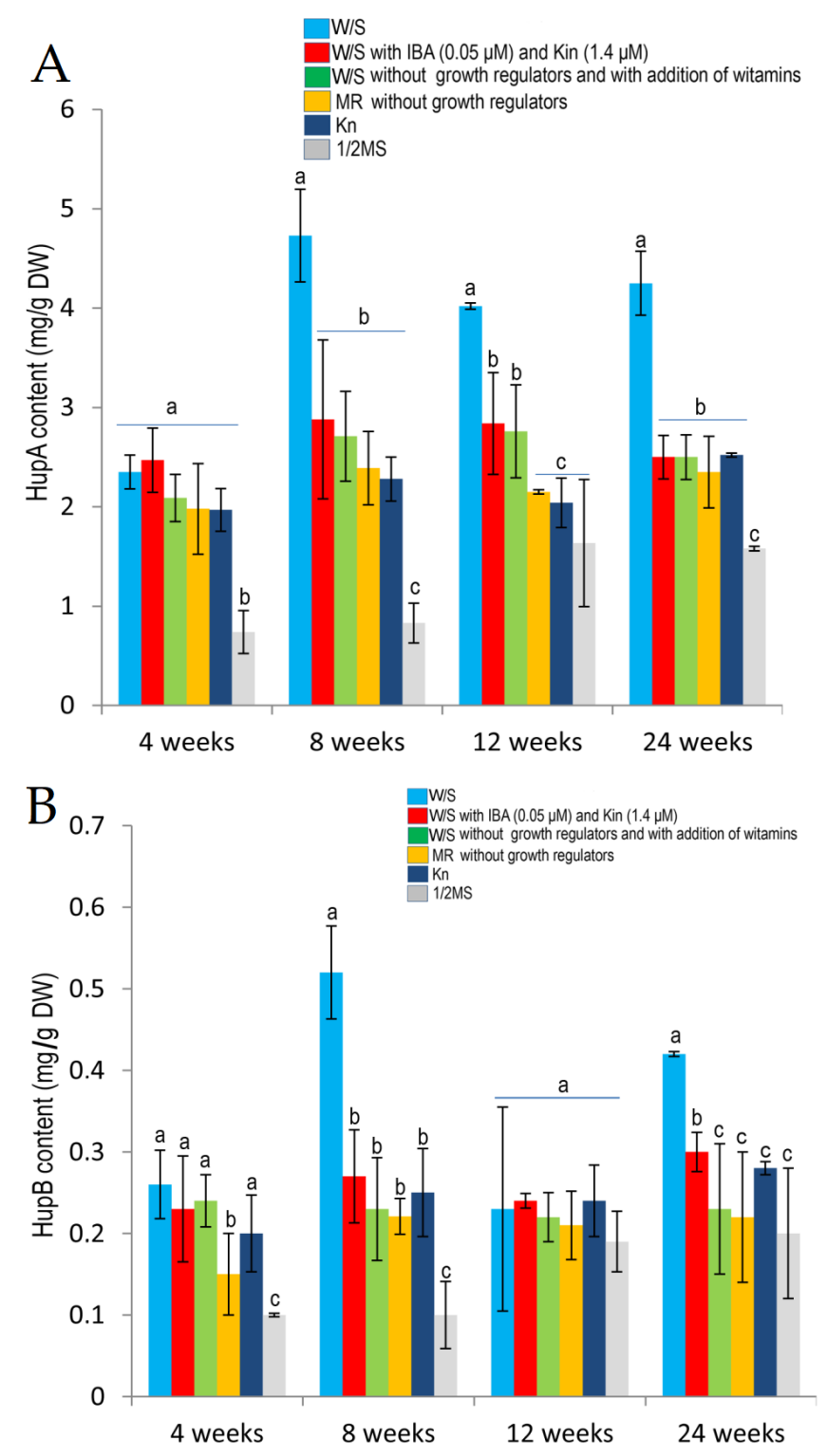

Figure 7. Total content of $\operatorname{HupA}(\mathbf{A})$ and $\operatorname{HupB}(\mathbf{B})$ in prothallus from in vitro cultures after 4, 8, 12 and 24 weeks on different media. The results are means of three replicates $(n=3) \pm \mathrm{SD}$ and are from three independent experiments. Significantly different values are denoted by different lowercase letters $(p<0.05)$. The statistical evaluation of the effect of media and its composition on an alkaloids synthesis was evaluated in individual weeks (successively in weeks 4, 8, 12 and 24) but not between weeks. 
During the 24 weeks of the experiment, a high HupA content of gametophytes, which on average ranged from to $2.20 \pm 0.11$ to $2.67 \pm 0.25 \mathrm{mg} / \mathrm{g}$ DW, was observed on the other media according to Whittier and Storchova (W/S) [26], Moor (MR) medium as modified by Freeberg and Wetmore [27] and Knudson medium (Kn) [28] (Figure 7). The lowest HupA content was found in the gametophytes cultured on $\frac{1}{2}$ MS medium [17,29]. It ranged from $0.74 \mathrm{mg} / \mathrm{g}$ DW to $1.635 \mathrm{mg} / \mathrm{g}$ DW at 12 weeks of culture (mean content: $1.20 \pm 0.26 \mathrm{mg} / \mathrm{g} \mathrm{DW}$ ).

The content of huperzine $B$ in the gametophytes from in vitro culture ranged from $0.10 \mathrm{mg} / \mathrm{g}$ to $0.52 \mathrm{mg} / \mathrm{g}$ DW (Figure 7). As with HupA, the highest content of HupB in gametophytes was found at 8 weeks of culture on W/S medium without growth regulators. The mean HupB content of gametophytes during 24 weeks of culture was $0.36 \pm 0.05 \mathrm{mg} / \mathrm{g}$ DW.

With the other media, a comparable level of HupB biosynthesis was achieved for the entire length of culture, on average from $0.24 \pm 0.02$ to $0.26 \pm 0.03 \mathrm{HupB}$ per $1 \mathrm{~g}$ DW. (Figure 7). The lowest Hup B content was found in the gametophytes cultured on $\frac{1}{2}$ MS. It ranged from 0.1 to $0.2 \mathrm{mg} / \mathrm{g}$ at 24 weeks of culture (mean content for the entire culture length: $0.15 \pm 0.03 \mathrm{mg} / \mathrm{g} \mathrm{DW}$ ).

\section{Discussion and Conclusions}

This paper presents a protocol for a fast and effective in vitro axenic culture of Huperzia selago (L.) Bernh. ex Schrank et Mart. (=Lycopodium selago L., fir club moss, Huperziaceae Rothm) gametophytes (prothallus), which is the best available and rich source of huperzine A (HupA, selagine) and other alkaloids. These compounds have a considerable therapeutic potential and are being extensively investigated for uses as treatments for a number of diseases $[5,6,11,31,32]$. The major therapeutic interest described for HupA is as treatment for acetylcholine-deficit dementia, including Alzheimer's disease [6]. Our previous results [31,32] demonstrated for the first time that alkaloids from H. selago possess antioxidative properties and scavenge free radicals as well as prevent lipid and protein oxidation, presenting the desired mechanism of action in neurodegenerative disorders. These alkaloids might be a promising source of active constituents of novel treatments for Alzheimer's and Parkinson's diseases $[6,8]$. Importantly, $H$. selago is the only European and North American species which contains HupA $[17,23]$. Studies have shown that the plant is a rich source of HupA, much more abundant than the Chinese club moss Huperzia serrata.

To date, studies on in vitro cultures have been conducted with a limited number of club moss species. Moreover, in the literature, there are only a few protocols for the propagation of sporophytes of HupA-containing club mosses and no effective protocols for the prothallus culture [23]. Up to now, club moss gametophytes from natural populations have been only infrequently described and in very rare cases they were obtained in vitro, but they have not been effectively used for the biosynthesis of secondary metabolites [23]. The first studies on the biosynthesis of HupA were conducted by Szypuła et al. [17,20,25] and Ma and Gang [24]. Szypuła et al. [17] presented a protocol for the establishment and maintenance of in vitro culture of Huperzia selago sporophytes from shoot explants (Figure 1). Using the method of indirect somatic embryogenesis, the authors obtained somatic embryos which after 6 months in culture produced sporophytes with the highest HupA content reported to date in Lycopods, as much as $3.33 \mathrm{mg} / \mathrm{g}$ DW. Other research groups established in vitro cultures of $H$. serrata and a few other closely related HupA-producing species [24]. The obtained Phlegmariurus squarrosuus tissues were found to produce satisfying amounts of HupA (from 0.312 to $0.675 \mathrm{mg} / \mathrm{g}$ DW in gametophytes and from 0.434 to $0.675 \mathrm{mg} / \mathrm{g}$ DW in sporophytes). Ishiuchi et al. [19] evaluated the alkaloid content in samples of 11 Huperzia species cultivated in greenhouses and in vitro. $H$. pinifolia in vitro culture was established and the biomass was assessed for alkaloid content (the maximum HupA content was $0.286 \mathrm{mg} / \mathrm{g}$ DW). In vitro cultures of the remaining Huperzia species were also initiated but the growth of plant tissue was not satisfactory. Of the 11 species evaluated, HupA was produced by the sporophytes of 10 species. The highest HupA content was found in H. pinifolia $(1.765 \mathrm{mg} / \mathrm{g}$ DW), followed by H. nummulariifolia $(1.69 \mathrm{mg} / \mathrm{g}$ DW). These results demonstrate that the maximum HupA content in the evaluated species was approximately 26 times [17] and 13 times [19] 
higher than the mean HupA level in $H$. serrata whole plant and 10 times higher than the maximum HupA content in H. serrata sporophytes characterized by the most biosynthesis of HupA.

In nature, the gametophytes of different club moss species are deeply subterranean (gametophyte development may take place even $20 \mathrm{~cm}$ below the surface of the ground), holosaprophytic and mycotrophic [33]. Usually, they are tubercular, conical in shape and devoid of chlorophyll [23,27,33]. In the genus Lycopodiella Holub, the prothallia possess chloroplasts [23]. The average prothallus is $8 \mathrm{~mm}$ long and $4 \mathrm{~mm}$ wide, but some may be as long as $20 \mathrm{~mm}$ and $5 \mathrm{~mm}$ wide [34]. Aggregates of antheridia and archegonia form the upper lobed crown region. Generally, the gametophytes are monoecious (bisexual), but some possess antheridia only [35]. The vegetative part of the prothallus is made of four layers: the outermost epidermis with heavily cutinized walls and trichomes which are epidermal outgrowths, the cortical layer beneath the epidermis, composed of up to eight rows of ovoid cells with a high intracellular content of fungal hyphae, and the palisade layer, which consists of one row of strongly elongated cells at right angles to the prothallus surface and serves as storage tissue. The parenchymatous central core is the innermost layer [35]. In nature, the germinating gametophyte does not live independently after it has divided into a few cells [27]. Association with fungi is obligatory for further gametophyte development as the mycelium of the fungus developing in the prothallus is in direct contact with mycelium in the soil and soluble nutrients found in the humus pass into the cells of the prothallus. In nature, the spore germination takes 2-3 years and the gametophyte maturation will take another 12-15 years [33]. Freeberg and Wetmore [27] and Freeberg [36,37] described the gametophytes of Lycopodium grown in vitro. Other partially successful cultures involved the gametophytes of Lycopodium obscurum [38], L. digitatum [39], L. lucidulum [40] and $H$. selago [26]. In the present study an efficient in vitro $H$. selago prothallus induction system was established on different Moore (MR) media as modified by Freeberg and Wetmore [27] and Whittier and Storchova [26], Knudson [28], and Murashige and Skoog (MS) [29] with or without growth regulators, supplemented with 2.5 or $5 \mathrm{~g} / \mathrm{L}$ glucose and different concentrations (0.05-1.4 $\mu \mathrm{M})$ of growth regulators, i.e., auxins (IBA) and cytokinins (kinetin), in the dark. Gametophyte cultures were initiated using spores obtained from populations growing in the wild. Their harvesting does not deplete the natural populations and is safe for club moss species threatened with extinction or for small local populations. Importantly, spore disinfection according the protocol developed specifically for the present study allowed tissue cultures free from bacterial and fungal contamination to be established and maintained. Achieving axenic cultures of the sporophytes of $H$. selago and other club mosses is the most challenging step $[17,23,25]$. Club mosses are mycorrhizal plants and their aboveground tissues are colonized by endophytic bacteria and fungi. They are found in gametophytes and sporophytes-in the mesophyll, air spaces between the cells of the cortex and in the cells of vascular tissues [17,23,37]. High mycorrhizal and endophytic species diversity encountered with club mosses considerably limits the use of sporophyte explants (shoot fragments or propagules) to initiate tissue cultures. Sporophytes used for that purposes require complicated and time-consuming disinfection procedures involving surface disinfection and intratissue antibiotic treatment, which, however, destroy some of endophytic species only $[17,20,23]$. According to the published literature, approximately $10 \%$ of explants in established cultures of long duration reveal the signs of contamination [17,19]. When commercial bulk-scale long-term tissue cultures are considered, the contamination issue would considerably impact the use of sporophytes for alkaloid production. So far, there has been only one method of sporophyte regeneration, i.e., somatic embryogenesis, which allows axenic Lycopod cultures to be established and maintained. To date, somatic embryogenesis has been described for just two Lycopodiaceas species, Lycopodiella inundata [41] and Huperzia selago [17], and of these, only $H$. selago can synthesize HupA. The use of somatic embryogenesis is, however, difficult, time-consuming and not very effective, although the sporophytes regenerated from somatic embryos contained $3.33 \mathrm{mg} / \mathrm{g}$ DW of HupA, the highest so far obtained amount of HupA [17]. In the present study, we wanted to determine the effects of culture conditions on the increase of gametophyte tissue mass and alkaloid synthesis levels. Low nutrient culture media proved to be suitable for successful gametophyte culture. Those were the 
media according to Whittier and Storchova [26], in fact, modifications of Moore medium which was used by Freeberg and Wetmore [27] and Freeberg [36] in the first reported in vitro cultures of club mosses. The choice of growth regulators was guided by earlier published reports of in vitro cultures of sporophytes of different club moss species, including the paper by Atmane et al. [41] on somatic embryogenesis in Lycopodiella inundata. In the sporophyte cultures of H. selago, supplementation of MS medium with IBA and kinetin was usually phytotoxic for fragments of $H$. selago shoots obtained from sporophytes growing in the wild [17]. However, in the cultures of gametophytes, supplementation of W/S medium with $0.05 \mu \mathrm{M}$ IBA and $1.4 \mu \mathrm{M}$ kinetin stimulated prothallus maturation and development of the gametangia. Similarly, Atmane et al. [41] observed that addition of IBA $(0.05 \mu \mathrm{M})$ and kinetin $(1.4 \mu \mathrm{M})$ to MS medium stimulated callus proliferation in the culture of Lycopodiella inundata shoots. The results of the few studies on tissue cultures of club mosses demonstrate that, apart from the endogenous properties of the explants, the success of the culture largely depends on the suitable composition of the basal medium, the growth regulators used and the source of nitrogen and the form in which it is presented. Nitrogen in the form of ammonium nitrate has long been known to determine the direction of explant morphogenesis [42-44]. It stimulates somatic embryogenesis, but the mechanism of this phenomenon remains unclear. It is generally assumed that substances supplying reduced nitrogen can stimulate protein synthesis and in this way impact morphogenesis [43-45]. The published literature suggests that such components of a culture medium as mineral salts or vitamins play a limited role [17,42-45]. As demonstrated in the present study, the use of MS medium rich in reduced nitrogen produced the least increase in biomass growth. Similarly, MS medium proved not suitable for sporophyte cultures [25]. The fastest gametophyte biomass growth was observed on $\mathrm{W} / \mathrm{S}$ media without growth regulators. The growth rate of $H$. selago gametophytes calculated on a fresh and dry weight basis was nearly 15 -fold higher than the growth rate of sporophytes obtained from shoot fragments at the same length of culture (6 months) and nearly twice as high as the growth rate in the cultures of sporophytes obtained from propagules via somatic embryogenesis $[17,23,25]$.

To date, no procedures have been developed for the synthesis and obtaining alkaloids in tissue cultures of club mosses on a commercial scale, while published studies show that gametophyte culture may be a simpler, more efficient and less expensive method of alkaloid biosynthesis than sporophyte culture.

The present study shows that the tissues of $H$. selago gametophytes are capable of synthesizing alkaloids, including HupA and HupB. There are no earlier studies of secondary metabolites produced by $H$. selago gametophytes, although there has been one trial using in vitro culture of Phlegmariurus squarrosuus metabolites for the biosynthesis of HupA, with a HupA yield at 6 and 12 months of $0.312 \mathrm{mg} / \mathrm{g}$ to $0.675 \mathrm{mg} / \mathrm{g}$ DW. In the present study, the biosynthesis of HupA and HupB by $H$. selago gametophytes was maintained throughout the whole experiment (6 months). HPLC-DAD and LC-MS analyses demonstrated that the qualitative composition of major alkaloids found in the gametophytes was similar to the alkaloid complex in the sporophyte tissues $[17,20]$. Importantly, the amount of HupA in the cultured gametophytes was on average nearly double the amount of HupA in the investigated sporophytes of various club moss species procured from their natural habitats. As much as up to $4.73 \mathrm{mg}(0.47 \%)$ of HupA per $1 \mathrm{~g}$ DW was found in the gametophytes from in vitro cultures. Before that, the highest HupA content was found in the sporophytes cultured from somatic embryos, i.e., $3.33 \mathrm{mg} / \mathrm{g}$ DW (0.33\%) [17]. The results demonstrate that by using gametophytes it is possible to increase HupA biosynthesis by approximately $42 \%$ compared to sporophyte culture. Considering that the mean content of Hup A in the sporophytes of $H$. serrata ranges from 0.0047 to $0.025 \%$ [6], with $H$. selago gametophytes the yield of the alkaloid is even 35 -fold higher than in $H$. serrata.

There are not many published studies on the HupB content in plant material or papers comparing the proportions of HupA and HupB in plants. HupB was earlier found in a limited number of club moss species, but the exact levels have been determined only recently [5,46]. According to Xu et al. [46], H. selago sporophytes from populations in Iceland contained approximately 0.006 to $0.2 \mathrm{mg} \mathrm{HupB}$ in 1 $\mathrm{g}$ of plant material. The exact relationship between HupA and HupB contents in investigated H. selago 
plant material is not known, but sporophytes from the Icelandic populations contain several hundred times less HupB than HupA in the same plant material [46]. The content of HupB in the H. selago gametophytes we obtained in vitro ranged from approximately $0.10 \mathrm{mg} / \mathrm{g}$ DW to $0.52 \mathrm{mg} / \mathrm{g} \mathrm{DW}$, which reflects very efficient biosynthesis of this alkaloid compared to the sporophytes of the same species.

According to the published literature, at least 13 alkaloids are present in $H$. selago tissues, including acrifoline, 12-epilycodoline (pseudoselagine), lycodoline, licopodine, selagoline, serratidinina, $6 \beta$-hydroxyhuperzine $\mathrm{A}, \alpha$ - and $\beta$-obscurine, huperzine $\mathrm{B}$, serratine and lucidoline [3,47-52]. In the present study, HPLC-HR-MS analyses of the alkaloid extracts from the gametophytes demonstrated a number of alkaloids which are either not present in $H$. selago sporophytes or their presence has not been confirmed. These are deacetylfawcettine, fawcettimine, 16-hydroxyhuperzine B, deacetyllycoclavine, annopodine, lycopecurine, des- $\mathrm{N}$-methylfastigiatine and flabelline. The presence of annopodine is an interesting finding since until now it has been considered as characteristic of the Lycopodium sensu stricto clade and thought to be limited to the Lycopodium annotinum species [5,23], while according to some authors, the group of taxa which includes L annotinum constitutes a distinct genus of Spinulum Haines. Their opponents point out the absence of significant differences in analyses using molecular markers which would support distinguishing of a new genus. Analyses using molecular data demonstrate that the genus Huperzia is the oldest club moss group, while H. selago is the oldest representative of the genus, taxonomically remote from the Lycopodium clade and with a different evolutionary lineage [23]. The presence of annopodine in the $H$. selago gametophytes would be an instance of chemical convergence rather than of chemotaxonomic relationship, although the biosynthesis of all club moss alkaloids follows a similar pathway with lysine acting as a precursor. Of the alkaloids found in $H$. selago sporophytes, in addition to HupA and HupB, the gametophytes contain four: $6 \beta$-hydroxyhuperzine A, serratinidine, lycopodine and selagoline. Interestingly, these alkaloids are not among approximately 90 alkaloids so far isolated from $H$. serrata $[5,15,16,23]$.

The results of the present study and earlier findings reported by Atmane et al. [41], Szypuła et al. [17,23], Ma and Gang [24] and Ishiuchi et al. [19] indicate that in tissue cultures the life cycle of club mosses is dysregulated to a greater or lesser extent since the explants are not controlled by the regulatory mechanisms of the whole plant and may be subjected to stresses such as excess or deficiency of sugars or growth regulators in the medium or its hydration status. In practice, when studying the biosynthesis of pharmacologically active compounds, this specific, altered and manipulated life cycle may be utilized to study the factors controlling the periodic developmental stage-related variations in the biosynthesis of selected alkaloids in sporophytes or gametophytes. In the future, exact knowledge of the life cycle alterations under experimental conditions as well as a clear understanding of the typical life cycle and its numerous modifications in vivo could be the key to the choice of those tissues and organs of club mosses which are best suited to isolating alkaloids.

\section{Materials and Methods}

\subsection{Reagents and Standards}

The following reagents and standard substances were used in the tests: Acetonitrile HPLC grade, Methanol HPLC grade Chromasolv ${ }^{\circledR}$, Sodium hexafluorophosphate $\left(\mathrm{NaPF}_{6}\right)$ and Ammonium acetate. Cellulase and Pectinase were purchased from Sigma-Aldrich Chemie GmbH (Steinheim, Germany). HPLC grade water was purchased from Merck KGaA (Darmstad, Germany). LC-MS $\mathrm{H}_{2} \mathrm{O}(18 \Omega)$ grade was purchased from Millipore Merck KGaA (Darmstadt, Germany). LC-MS acetonitrile grade was purchased from Merck. Chloroform, diethyl ether, sodium chloride, ethyl alcohol, formaldehyde $37 \%$ and glacial acetic were purchased from $\mathrm{POCH}$ (Gliwice, Poland). Bacto ${ }^{\mathrm{TM}}$ Agar was purchased from Becton, Dickinson \& Company, (Franklin Lakes, New Jersey, USA). IAA, IBA and kinetin were purchased from Grand Island Biological Company (New York, USA). Plant Preservative Mixture (PPM) was purchased from Plant Cell Technology (Washington, D.C., USA). Toluidine Blue was purchased from Across Organics (Geel, Belgium). Periodic acid and Schiff's reagent for microscopy was purchased 
from Merck KGaA. Huperzine A and Huperzine B standards were purchased from ChromaDex Inc. (Laguna Hills, CA, USA).

\subsection{Plant Material and Establishment of In Vitro Culture}

Huperzia selago gametophyte in vitro cultures were initiated using spores obtained from shoot fragments of sporangia-bearing sporophytes procured from populations in the Babia Góra National Park ( $49^{\circ} 34^{\prime} 24^{\prime \prime}$ N $19^{\circ} 31^{\prime} 46^{\prime \prime}$ E), The Beskids, Poland (Figure 1). The plants were harvested at 30-day intervals, from April through November 2013.

Voucher specimens, including sporophytes with sporangia, were taken and deposited in the Herbarium at the Faculty of Biology, University of Warsaw (WA) (Nos 0000074900). The plant was identified by Dr. W. Szypuła, according to the literature data $[23,53]$.

The plants were sorted and removed to the laboratory. They were cleansed of dirt and debris, transferred to Petri dishes lined with filter paper and incubated at room temperature for a few days to achieve spore release. The spores were passed through a $0.5 \mathrm{~mm}$ sieve and afterwards stored in the dark at room temperature for up to three weeks and then used to initiate gametophyte cultures.

Prior to establishing in vitro cultures, the spores were disinfected using our own method of surface disinfection developed for in vitro culture of $H$. selago sporophytes [25], which consisted of soaking the spores in 70\% ethanol $(v / v)$ for $1 \mathrm{~min}$, followed by sodium hypochlorite (ACE, Procter \& Gamble Cincinnati, Ohio, USA) with $\mathrm{H}_{2} \mathrm{O}(1: 5 \mathrm{v} / \mathrm{v}$-which is $0.8 \%$ sodium hypochlorite solution) for $10 \mathrm{~min}$ and next $7 \% v / v \mathrm{H}_{2} \mathrm{O}_{2}$ for 5 min.

In nature, the germination of $H$. selago spores takes approximately 3 to 5 years and that is why the next mandatory step involved mechanical or chemical scarification treatment of the spores to overcome dormancy and speed up germination. The method described by Freeberg and Wetmore [27] was used or the spores were soaked for $24 \mathrm{~h}$ at $20^{\circ} \mathrm{C}$ in the dark in the solution of growth regulators $(100 \mu \mathrm{M}$ IAA and $50 \mu \mathrm{M}$ kinetin). Moreover, the spores were separated from the growth regulator solution using fluted filter papers and gravity filtration and again soaked in water with $1 \%(v / v)$ cellulase and $0.5 \%(v / v)$ pectinase for $6 \mathrm{~h}$ at $24{ }^{\circ} \mathrm{C}$.

After disinfection and the stage of dormancy break, the spores $(500 \mathrm{mg})$ were suspended in $20 \mathrm{~mL}$ of sterile distilled water and next $2 \mathrm{~mL}$ of the suspension was transferred to growth media for germination. The germination of each portion of spores, collected in different seasons, was evaluated on the following tested media: W/S [26] without growth regulators, W/S with IBA $(0.05 \mu \mathrm{M})$ and kinetin (Kin) $(1.4 \mu \mathrm{M}), \mathrm{W} / \mathrm{S}$ without growth regulators and with addition of vitamins, and on Moore medium (MR) [27] without growth regulators. In addition, the media according to Knudson (Kn) [28] and Murashige and Skoog ( $\frac{1}{2}$ MS) [29] with half strength mineral salt content, both without growth regulators, were tested. The W/S and MR media were supplemented with glucose $(2.5 \mathrm{~g} / \mathrm{L})$ and agar (1.1\%). The $\frac{1}{2}$ MS medium was supplemented with $10 \mathrm{~g} / \mathrm{L}$ saccharose and $0.8 \%$ agar. All media were adjusted to $\mathrm{pH} 5.9$ prior to autoclaving. Plant Preservative Mixture ${ }^{\mathrm{TM}}$ (PPM ${ }^{\mathrm{TM}}$; Plant Cell Technology, Washington, USA) $2 \mathrm{~mL} / \mathrm{L}$ was added to the media to prevent microbial contamination during the stage of spore germination, which lasted several months.

The control cultures were initiated from spores collected in the same period of time (from April through November) but which were not scarified mechanically or treated with growth regulators or the enzymes cellulase and pectinase. Before sowing they were soaked in water without growth regulators for $24 \mathrm{~h}$ at $20^{\circ} \mathrm{C}$ in the dark.

The spores, on all the media listed above, were incubated in a phytotron at $18 \pm 1{ }^{\circ} \mathrm{C}$ (day) and $16 \pm 1{ }^{\circ} \mathrm{C}$ (night) with light at $100 \mu \mathrm{M} / \mathrm{m}^{2} / \mathrm{s}$ and $14 \mathrm{~h}$ photoperiod or without light, at the same temperature.

After the germination of spores, $5 \mathrm{~g} / \mathrm{L}$ glucose and $1.1 \%$ agar were added to the MR and W/S media. The gametophytes were transferred on to a fresh medium every 3 months. The prothallia were incubated in a phytotron at $18 \pm 1{ }^{\circ} \mathrm{C}$ (day) and $16 \pm 1{ }^{\circ} \mathrm{C}$ (night) in the dark. 


\subsection{Morphological Analysis of Huperzia Selago Prothallus Cultures}

To observe all stages of gametophyte development, a Discovery V12 (Zeiss) stereo light and fluorescent microscope with Apochromat S $0.63 \times$ and PlanApo S $1.5 \times$ lenses equipped with a Nikon D90 camera was used. Scanning electron microscopy (SEM) was used for morphological observation of the prothallus. Various prothallus specimens were directly inserted inside an environmental scanning electron microscope (ESEM) QUANTA 200 FEI (FEI Europe B.V., Eindhoven, Netherlands), suitable for observation of biological material, without prior fixation. Secondary electron images (SE) were taken at $20 \mathrm{kV}$. Photographs were taken at different magnifications. At 4, 8, 12 and 24 weeks in culture, the index of gametophyte fresh and dry biomass growth (WP) was calculated for 30 prothalli and the calculation was repeated in triplicate. The WP value was calculated according to Street and Henshaw [54] where $\mathrm{WP}=$ final plant mass $(\mathrm{g})-$ initial plant mass $(\mathrm{g}) /$ initial plant mass $(\mathrm{g}) \times 100$. The final results are presented as the mean WP value for the entire harvest period.

\subsection{Histological Analysis}

Analyses were carried out on juvenile and mature prothalli cultured on W/S medium without growth regulators. Their stage of maturity was identified by morphological features described by Whittier and Storchova [26]. For each analysis, at least 10 prothalli were used. Photographs shown in this paper are representative examples (Figure 3). The samples (prothallus) were vacuum-infiltrated with FAE fixative with formaldehyde 37\%:100\% glacial acetic acid:ethanol 50\%, 6.5:3.5:100 mL $(v / v / v)$ for $72 \mathrm{~h}$ at room temperature [39]. Fixed tissue was dehydrated in a series of ethanol concentrations: 40, 50, $70,90,100 \%(v / v)$ (30 min each bath). After dehydration and wax (Paraplast Plus, McCormic Scientific) embedding 5-10 $\mu \mathrm{m}$ specimens were cut. Sections were stained with PAS (periodic acid-Schiff) or double stained with PAS and NBB (Naphtol Blue Black). PAS specifically stained polysaccharides red, and NBB stained soluble and reserve proteins bluish-black. Observations and slides showing important features were made with a light Zeiss Axio Lab A1 microscope equipped with a Canon EOS 1100D camera. Additionally, some microscopic analyses were based on light blue autofluorescence of mature archegonia and red autofluorescence of chlorophyll with a standard filter set (excitation/emission $358 / 461 \mathrm{~nm}$ ) with the same microscope.

\subsection{Alkaloid Extraction and Determination}

\subsubsection{Preparation of Extracts and Their Purification}

An alkaloid fraction was obtained using a conventional procedure from methanol extract, as previously reported by Szypuła et al. [20]. Each sample of powdered plant sample of prothallus $(0.25 \mathrm{~g})$ was extracted with methanol of analytical purity grade $(5 \mathrm{~mL})$ for $30 \mathrm{~min}$, repeated three times until the eluate was negative to Dragendorff's reagent. Then, the combined extracts were filtered. The extraction was carried out in a RK 100H ultrasonic cleaning bath (Bandelin Sonorex, Berlin, Germany), with a mean operating frequency of $35 \mathrm{kHz}$ and the power adjusted to $160 \mathrm{~W}$, at $40{ }^{\circ} \mathrm{C}$. The combined filtrates were evaporated under reduced pressure. Next, the dry residue was dissolved in $10 \mathrm{~mL}$ of $2.5 \%$ hydrochloric acid and purified by shaking twice with chloroform and then with ethylic ether. The water phase was rendered basic with $25 \%$ ammonia solution ( $\mathrm{pH}$ 9), salted out with sodium chloride and then exhaustively extracted with chloroform. In the last stage, the combined chloroform extracts were evaporated to dryness. The dry residue was dissolved in $1 \mathrm{~mL}$ of methanol (HPLC purity grade) and used in the HPLC-DAD assay.

\subsubsection{Qualitative and Quantitative HPLC-DAD Analyses of HupA and HupB}

Qualitative and quantitative HPLC-DAD analyses of HupA and HupB were performed on a Shimadzu system (Kyoto, Japan) consisting of a UV-VIS and SPD-10A DAD 340S detector, LC-10AD pump and LC solution software. A Hypersil GOLD column, $\mathrm{C}_{18} 250 \times 4.6 \mathrm{~mm}$, and a Hypersil GOLD precolumn, $5 \mathrm{UM} 10 \times 4 \mathrm{~mm}$, were used. The mobile phase consisted of (A) water with the addition of 
$30 \mathrm{mM} \mathrm{NaPF}_{6}$ and (B) acetonitrile. The following gradient was applied: $0-5 \mathrm{~min} 0 \rightarrow 25 \% \mathrm{~B}, 5-20 \mathrm{~min}$ $25 \rightarrow 45 \%$ B , 20-30 min $45 \rightarrow 80 \%$ B [20]. Column temperature: $24 \pm 1{ }^{\circ} \mathrm{C}$, flow rate of the mobile phase: $1.0 \mathrm{~mL} / \mathrm{min}$, analysis duration: $30 \mathrm{~min}$, detection at wave lengths $\lambda=210,230,260,308 \mathrm{~nm}$. The HPLC-DAD analyses of HupA and HupB used in this work was previously validated [20].

\subsubsection{LC-MS Analysis of HupA and HupB}

A Shimadzu Prominence high-performance liquid chromatograph (HPLC) was used coupled with a LCMS-IT-TOF mass spectrometer (Shimadzu), equipped with an ion trap (IT), a time-of-flight (TOF) detector and an electrospray ionization (ESI) source. Mass spectra were recorded in the positive ion mode using LCMS solution software (Shimadzu).

Conditions for HPLC separation and detection of alkaloids were as follows: column Kinetex $\mathrm{C}_{18}$, $2.6 \mu \mathrm{m}, 2.1 \times 100 \mathrm{~mm}$, Phenomenex, injection volume: 5 or $10 \mu \mathrm{L}$, oven column temperature: $40^{\circ} \mathrm{C}$, flow rate: $0.15 \mathrm{~mL} / \mathrm{min}$, analysis duration: $70 \mathrm{~min}$, PDA detection at wave lengths $\lambda=200-800 \mathrm{~nm}$. The mobile phase consisted of (A) water with the addition of $5 \mathrm{mM} \mathrm{HCOONH}_{4}(\mathrm{pH} \mathrm{4.0)}$ and (B) acetonitrile. The following gradient was applied: $0-1 \min 0 \rightarrow 3 \% \mathrm{~B}, 3-40 \mathrm{~min} 3 \rightarrow 30 \% \mathrm{~B}, 40-50 \mathrm{~min}$ $30 \rightarrow 95 \%$ B, $50-55 \min 95 \%$ B, 55-57 $\min 95 \rightarrow 3 \%$ B, equilibrium time- 13 min in 3\% B.

Conditions for the mass spectrometer were as follows: polarity positive: mass range $m / z 100-800 \mathrm{Da}$, ion accumulation: $10 \mathrm{~ms}$, interface temperature: $220^{\circ} \mathrm{C}$, heat block temperature: $220^{\circ} \mathrm{C}$, nebulizing gas flow: $1.5 \mathrm{~L} / \mathrm{min}$, drying gas pressure: $100 \mathrm{kPa}$, IS: $+4.5 \mathrm{kV}$.

The calibration mixture was used to calibrate the TOF detector of the LCMS-IT-TOF mass spectrometer. The sample was prepared by dissolving $5 \mathrm{mM}$ of buffer $\mathrm{HCOONH}_{4}$ in 1:1 ratio in the mixture of ACN and spinning in a centrifuge, and the supernatant was transferred to an HPLC injection vial.

\subsection{Statistical Analysis}

Data are expressed as mean values \pm S.E.M. Multiple comparisons were analyzed using Kruskal-Wallis one-way analysis of variance by ranks. The statistical analyses were performed using STATISTICA StatSoft (Poland). Statistical significance was accepted at $p<0.05$.

Author Contributions: The following declarations about authors' contributions to the research have been made: W.J.S.: concept of the study, project administration and methodology, all laboratory research and data analyses, writing and revision of the manuscript; B.W. and A.M.: LC-MS analysis; A.P.: writing-review of manuscript. All authors have read and agreed to the published version of the manuscript.

Funding: The authors thank Babia Góra National Park authorities for permission to undertake the research in the park.

Conflicts of Interest: The authors declare no conflict of interest.

\section{References}

1. Valenta, Z.; Yoshimura, H.; Rogers, E.; Ternbah, M.; Wiesner, K. The structure of selagine. Tetrahedron Lett. 1960, 1, 26-33. [CrossRef]

2. Yoshimura, H.; Valenta, Z.; Wiesner, K. A rigorous proof of the selagine structure. Tetrahedron Lett. 1960, 1, 14-17. [CrossRef]

3. Ayer, W.A.; Browne, L.M.; Orszanska, H.; Valenta, Z.; Liu, J.-S. Alkaloids of Lycopodiumselago. On the identity of selagine with huperzine A and the structure of a related alkaloid. Can. J. Chem. 1989, 67, 1538-1540. [CrossRef]

4. $\quad$ Liu, J.-S.; Zhu, Y.-L.; Yu, C.-M.; Zhou, Y.-Z.; Han, Y.-Y.; Wu, F.-W.; Qi, B.-F. The structures of huperzine A and $\mathrm{B}$, two new alkaloids exhibiting marked anticholinesterase activity. Can. J. Chem. 1986, 64, 837-839. [CrossRef]

5. Ma, X.; Gang, D.R. The Lycopodium alkaloids. Nat. Prod. Rep. 2004, 21, 752. [CrossRef]

6. Ferreira, A.; Rodrigues, M.; Fortuna, A.; Falcão, A.; Alves, G. Huperzine A from Huperzia serrata: A review of its sources, chemistry, pharmacology and toxicology. Phytochem. Rev. 2014, 15, 51-85. [CrossRef] 
7. Zhang, H.; Zheng, C.Y.; Yan, H.; Wang, Z.F.; Tang, L.L.; Gao, X.; Tang, X.C. Potential therapeutic targets of huperzine A for Alzheimer's disease and vascular dementia. Chem. Interactions 2008, 175, 396-402. [CrossRef]

8. Zhang, H.Y. New insights into huperzine A for the treatment of Alzheimer's disease. Acta Pharm. Sinic. 2012, 33, 1170-1175. [CrossRef]

9. Wang, R.; Yan, H.; Tang, X.C. Progress in studies of huperzine A, a natural cholinesterase inhibitor from Chinese herbal medicine1. Acta Pharmacol. Sin. 2006, 27, 1-26. [CrossRef]

10. Wang, R.; Zhang, H.; Tang, X.C. Huperzine A attenuates cognitive dysfunction and neuronal degeneration caused by $\beta$-amyloid protein-(1-40) in rat. Eur. J. Pharmacol. 2001, 421, 149-156. [CrossRef]

11. Zhang, H.; Tang, X.C. Neuroprotective effects of huperzine A: New therapeutic targets for neurodegenerative disease. Trends Pharmacol. Sci. 2006, 27, 619-625. [CrossRef]

12. Feng, S.; Xia, Y.; Han, D.; Zheng, C.; He, X.; Tang, X.; Bai, D. Synthesis and acetylcholinesterase inhibition of derivatives of huperzine B. Bioorg. Med. Chem. Lett. 2005, 15, 523-526. [CrossRef] [PubMed]

13. Ma, T.; Gong, K.; Yan, Y.; Zhang, L.; Tang, P.-F.; Zhang, X.; Gong, Y. Huperzine A promotes hippocampal neurogenesis in vitro and in vivo. Brain Res. 2013, 1506, 35-43. [CrossRef]

14. Xu, H.; Tang, X.C. [Cholinesterase inhibition by huperzine B]. Zhongguo yao li xue bao = Acta Pharmacol. Sin. $1987,8,18-22$.

15. Ma, R.; Tan, C.-H.; Zhu, D.; Gang, D.R. A survey of potential huperzine A natural resources in China: The Huperziaceae. J. Ethnopharmacol. 2006, 104, 54-67. [CrossRef] [PubMed]

16. Ma, X.; Tan, C.-H.; Zhu, D.; Gang, D.R.; Xiao, P. Huperzine A from Huperzia species-An ethnopharmacolgical review. J. Ethnopharmacol. 2007, 113, 15-34. [CrossRef]

17. Szypuła, W.; Pietrosiuk, A.; Suchocki, P.; Olszowska, O.; Furmanowa, M.; Kazimierska, O. Somatic embryogenesis and in vitro culture of Huperzia selago shoots as a potential source of huperzine A. Plant Sci. 2005, 168, 1443-1452. [CrossRef]

18. Wu, Q.; Gu, Y. Quantification of huperzine A in Huperzia serrata by HPLC-UV and identification of the major constituents in its alkaloid extracts by HPLC-DAD-MS-MS. J. Pharm. Biomed. Anal. 2006, 40, 993-998. [CrossRef]

19. Ishiuchi, K.; Park, J.-J.; Long, R.M.; Gang, D.R. Production of huperzine A and other Lycopodium alkaloids in Huperzia species grown under controlled conditions and in vitro. Phytochemistry 2013, 91, 208-219. [CrossRef]

20. Szypuła, W.J.; Kiss, A.K.; Pietrosiuk, A.; Świst, M.; Danikiewicz, W.; Olszowska, O. Determination of Huperzine A in Huperzia selago Plants from Wild Population and Obtained in In Vitro Culture by High-Performance Liquid Chromatography Using a Chaotropic Mobile Phase. Acta Chrom. 2011, 23, 339-352. [CrossRef]

21. Borloz, A.; Marston, A.; Hostettmann, K. The determination of huperzine A in European Lycopodiaceae species by HPLC-UV-MS. Phytochem. Anal. 2006, 17, 332-336. [CrossRef]

22. Lim, W.H.; Goodger, J.Q.D.; Field, A.R.; Holtum, J.A.M.; Woodrow, I.E. Huperzine alkaloids from Australasian and southeast Asian Huperzia. Pharm. Biol. 2010, 48, 1073-1078. [CrossRef] [PubMed]

23. Szypuła, W.J.; Pietrosiuk, A. Production of Cholinesterase-Inhibiting Compounds in In Vitro Cultures of Club Mosses. In Plant Cell and Tissue Differentiation and Secondary Metabolites: Fundamentals and Applications; Ramawat, K.G., Ekiert, H.M., Goyal, S., Eds.; Springer International Publishing: Cham, Swizerland, 2019; pp. 1-40.

24. Ma, X.; Gang, D.R. In vitro production of huperzine A, a promising drug candidate for Alzheimer's disease. Phytochemistry 2008, 69, 2022-2028. [CrossRef]

25. Szypuła, W.; Mistrzak, P.; Olszowska, O. A new and fast method to obtain in vitro cultures of Huperzia selago (Huperziaceae) sporophytes, a club moss which is a source of huperzine A. Acta Soc. Bot. Pol. 2013, 82, 313-320. [CrossRef]

26. Whittier, D.P.; Štorchová, H. The Gametophyte of Huperzia selago in Culture. Am. Fern J. 2007, 97, 149-154. [CrossRef]

27. Freeberg, J.A.; Wetmore, R.H. Gametophytes of Lycopodium as grown in vitro. Phytomorphology 1957, 7, 204-217.

28. Knudson, L. Nonsymbiotic Germination of Orchid Seeds. Int. J. Plant Sci. 1922, 73, 1-25. [CrossRef] 
29. Murashige, T.; Skoog, F. A revised medium for rapid growth and bioassays with tobacco tissue culture. Plant Physiol. 1962, 15, 473-497. [CrossRef]

30. Jerkowich, A.D.; Vivilecchia, R.V. Developmental of fast HPLC Methods. In HPLC for Pharmaceutical Scientists; Kazakevich, Y., Lobrutto, R., Eds.; Wiley-Interscience John Wiley \& Sons: Hoboken, NJ, USA, 2007; pp. 783-810.

31. Czapski, G.A.; Szypuła, W.; Kudlik, M.; Wilenska, B.; Kania, M.; Danikiewicz, W.; Adamczyk, A. Original article Assessment of antioxidative activity of alkaloids from Huperzia selago and Diphasiastrum complanatum using in vitro systems. Folia Neuropathol. 2014, 4, 394-406. [CrossRef]

32. Lenkiewicz, A.; Czapski, G.A.; Jeśḱko, H.; Wilkaniec, A.; Szypuła, W.; Pietrosiuk, A.; Uszyńska, A.M.; Adamczyk, A. Potent effects of alkaloid-rich extract from Huperzia selago against sodium nitroprusside-evoked PC12 cells damage via attenuation of oxidative stress and apoptosis. Folia Neuropathol. 2016, 2, 156-166. [CrossRef]

33. Eames, A.J. Illustrations of Some Lycopodium Gametophytes. Am. Fern J. 1942, 32, 1. [CrossRef]

34. Bruchmann, H. Das Prothallium von Lycopodium. Bot. Zentralblatt 1885, 21, 23-28.

35. Bruchmann, H. Über die Prothallien und die Keimpfl anzen Mehrerer europäischer Lycopodien, und Zwar über die von Lycopodium clavatum, L. annotinum, L. complanatum und L. selago; Friedrich \& Andreas Perthes: Gotha, Germany, 1898.

36. Freeberg, J.A. The apogamous development of sporelings of Lycopodium cernuum L., L. complanatum var. flabelliforme Fernald and L. selago L. in vitro. Phytomorphology 1957, 7, 217-229.

37. Freeberg, J.A. lycopodium prothalli and their endophytic fungi as studied in vitro. Am. J. Bot. 1962, 49, 530-535. [CrossRef]

38. Whittier, D.P. Gametophytes of Lycopodium obscurum as grown in axenic culture. Can. J. Bot. 1977, 55, 563-567. [CrossRef]

39. Whittier, D.P. Gametophytes of Lycopodium digitatum (Formerly L. Complanatum var. flabelliforme) as Grown in Axenic Culture. Int. J. Plant Sci. 1981, 142, 519-524. [CrossRef]

40. Whittier, P.; Webster, T.R. Gametophytes of Lycopodium lucidulum from Axenic Culture. Am. Fern J. 1986, 76, 48. [CrossRef]

41. Atmane, N.; Blervacq, A.; Michaux-Ferriere, N.; Vasseur, J. Histological analysis of indirect somatic embryogenesis in the Marsh clubmoss Lycopodiella inundata (L.) Holub (Pteridophytes). Plant Sci. 2000, 156, 159-167. [CrossRef]

42. Meijer, E.G.M.; Brown, D.C.W. Role of exogenous reduced nitrogen and sucrose in rapid high frequency somatic embryogenesis in Medicago sativa. Plant Cell, Tissue Organ Cult. (PCTOC) 1987, 10, 11-19. [CrossRef]

43. Trigiano, R.N.; May, R.A.; Conger, B.V. Reduced nitrogen influences somatic embryo quality and plant regeneration from suspension cultures of orchardgrass. Vitr. Cell. Dev. Boil.-Anim. 1992, 28, 187-191. [CrossRef]

44. Debeaujon, I.; Branchard, M. Somatic embryogenesis in Cucurbitaceae. Plant Cell Tissue Organ Cult. 1993, 34, 91-100. [CrossRef]

45. Gaj, M.D. Factors Influencing Somatic Embryogenesis Induction and Plant Regeneration with Particular Reference to Arabidopsis thaliana (L.) Heynh. Plant Growth Regul. 2004, 43, 27-47. [CrossRef]

46. Xu, M.; Heidmarsson, S.; Thorsteinsdottir, M.; Wasowicz, P.; Sun, H.; Deng, T.; Omarsdottir, S.; Olafsdottir, E.S. Infraspecific Variation of Huperzine A and B in Icelandic Huperzia selago Complex. Planta Med. 2018, 85, 160-168. [CrossRef] [PubMed]

47. Achmatowicz, O.; Rodewald, W. The alkaloids of Lycopodium selago. Bull. Acad. Polon. Sci. Classe III 1955, 3, 553-555.

48. Achmatowicz, O.; Rodewald, W. Alkaloidy rodzaju Lycopodium. III. Alkaloidy Lycopodium selago L. Rocz. Chem. 1956, 30, 232-242.

49. Rodewald, W.J.; Grynkiewicz, G. Alkaloidy rodzaju Lycopodium. VI. Alkaloidy Lycopodium selago L. Rocz. Chem. 1968, 42, 465-475.

50. Ayer, W.A.; Kasitu, G.C. Some new Lycopodium alkaloids. Can. J. Chem. 1989, 67, 1077-1086. [CrossRef]

51. Ma, X.-Q.; Jiang, S.-H.; Zhu, D.-Y. Alkaloid patterns in Huperzia and some related genera of Lyopodiaceae sensu lato occurring in China and their contribution to classification. Biochem. Syst. Ecol. 1998, 26, 723-728. [CrossRef] 
52. Stærk, D.; Larsen, J.; Larsen, L.A.; Olafsdottir, E.S.; Witt, M.; Jaroszewski, J.W.; Staerk, D. Selagoline, A new Alkaloid fromHuperzia Selago. Nat. Prod. Res. 2004, 18, 197-203. [CrossRef]

53. Valentine, D.H.; Moore, D.M. Lycopodiaceae L. In Flora Europea, 2nd ed.; Tutin, T.G., Burges, N.A., Chater, A.O., Edmondson, J.R., Heywood, V.H., Moore, D.M., Valentine, D.H., Walters, S.M., Webb, D.A., Eds.; Cambridge University Press: Cambridge, UK, 1993; Volume I, pp. 1-4.

54. Street, H.; Henshaw, G. Introduction and Methods Employed in Plant Tissue Culture. In Cells and Tissues in Culture Methods, Biology and Physiology; Elsevier BV: New York, NY, USA, 1966; Volume 3, pp. 459-532.

Sample Availability: Samples are not available from the authors.

(C) 2020 by the authors. Licensee MDPI, Basel, Switzerland. This article is an open access article distributed under the terms and conditions of the Creative Commons Attribution (CC BY) license (http://creativecommons.org/licenses/by/4.0/). 